\title{
In vitro Inductions of Gamma Ray Mutation for Fusarium Wilt Resistance and Characterization of Mutants in Regionally Grown Banana Cultivars
}

\author{
Rashmi Hegde $^{1 *}$, .G Prabhuling ${ }^{5}$, Kulpathi Hipparagi ${ }^{2}$, A.G. Babu ${ }^{5}$, \\ C.P Mansur ${ }^{3}$ and D. Satish ${ }^{4}$ \\ ${ }^{1}$ Department of Biotechnology and Crop Improvement, University of Horticultural Sciences, \\ Bagalkot, India \\ ${ }^{2}$ Department of Fruit Science, University of Horticultural Sciences, Bagalkot, india \\ ${ }^{3}$ Department of Agronomy, University of Agricultural Sciences, Dharwad, India \\ ${ }^{4}$ Department of Biotechnology and Crop Improvement, Arbhavi, University of Agricultural \\ Sciences, Dharwad, India \\ ${ }^{5}$ Centre for Horticulture Biotechnology, Directorate of Research, University of Horticultural \\ Sciences, Bagalkot, India \\ *Corresponding author
}

\section{A B S T R A C T}

\section{Keywords}

Mutation,

Screening,

Fusarium wilt, characterization,

SSR, disease

resistance

Article Info

Accepted:

12 February 2019

Available Online:

10 March 2019
Regionally grown banana cultivars are severely infected by several pathogens one such Fusarium oxysoporum f. sp. Cubense which causes significant crop losses in the fields. In this study fusarium wilt screening was carried out on gamma ray induced mutants and molecular characterization was done to assess the acquired resistance to Fusarium oxysoporum f. sp. cubense. From the screening we observed that gamma ray derived mutants are more sensitive in 25, 30 and 35 Gy. Whereas, several mutants obtained from 40 and 45 were resistant as comparable with untreated control. Similar analysis with molecular markers also revealed comparable results in screening. SSR primers showed resistance specific bands and were used for the testing variation among mutants, after confirming its reproducibility. Putative resistant, moderate resistant and susceptible mutants along with untreated control banana plants when amplified with Ma 3/2 and Ma 15 in Nanjanagudu Rasabale showed the presence of a major band at $150 \mathrm{bp}$ and $500 \mathrm{bp}$ and in Ma 1/17 and STMS 7 in Ney Poovan showed the presence 500 bp and 250 bp as major bands, this evidenced the occurrence of random mutations in genome.

\section{Introduction}

India being one of the centers of origin and diversity of Musa, is rich in its wealth. Natural intra-specific and inter-specific crosses among $M$. accuminata and $M$. balbisiana and long period of domestication under varying growing conditions have created high diversity in Indian bananas. The local cultivar diversity is more conspicuous with groups such as $\mathrm{AB}$ and $\mathrm{AAB}$ clones.

The Nanjanagudu Rasabale (Musa spp., AAB, silk subgroup) known for its unique taste has a huge demand across the country. But, conditions are not favorable enough for 
growing the banana and to match the huge demand that it generates (Kishore, 2016). The cultivar Nanjanagudu Rasabale geographical indication tagged and once leading cultivar of then Mysore province is under threat of extinction due to its susceptibility to Panama diseases (Pooja et al., 2013). The cultivar grown in around 600 acres of land in the district of Mysore, Karnataka, now confined to only 30 acres of land in isolated area (Khan, 2015). The variety now which is at the danger of extinct has to strictly bred by potential methodology to save and preserve as a germplasm.

Ney Poovan (AB) is the choicest diploid cultivar of banana, which is under commercial mono cultivation on a large scale especially in Karnataka and Tamil Nadu. Fruits are small, slender having a prominent beak and are arranged around the axis in a way that they bear a wind-blown appearance (Daniells et $a l ., 2001)$. Fruits are very attractive due to their bright yellow color with ivory white pulp. They retain their firmness upon ripening, thereby improving their overall appeal in the market. Owing to these superior characters, the variety has been included in the list of export suited banana varieties by National Research Center on Banana, Trichy. Recent studies have reported that this variety is able to produce bunches of appreciable size even under low moisture conditions (Ravi et al., 2013).

The Fusarium wilt (Panama Diseases) disease is the most important and wide spread in most Nanjanagudu Rasabale and Ney Poovan producing regions and cause considerable yield reduction to the tune of $50 \%$, if uncontrolled (Stover and Malo,1972).

The progress of banana improvement by conventional breeding methods has been relatively slow or even hindered due to narrow genetic variability resulting from its low female fertility (Silva et al., 2001; Pua, 2007; Bidabadi et al., 2010). Conventional breeding methods have been of limited success in Musa species due to parthenocarpy, polyploidy in many cultivars, and limited available information on genetics and genomics (Chopra, 2005; Capdeville et al., 2009).

\section{Materials and Methods}

Rising of shoot buds cultures and induction of mutations were carried out at centre of Horticulture Biotechnology, UHS, Bagalkot. Aseptic culture were subjected to gamma irradiation treatment at 25,30,35, 40 and 45 Gy at Baba Atomic Research Centre, Trombay using ${ }^{60} \mathrm{Co}$ as source of the gamma irradiation. Each treatment was replicated 3 times and about 30 multiple buds used for each treatment.

Raising of aseptic cultures and regeneration of plantlets

Aseptic cultures and platelets were raised following the protocol standardized by Kishore (2016) with some modifications. Shoot tip explants were incubated in MS liquid culture media supplemented with 4 $\mathrm{mg} / \mathrm{l} \mathrm{BAP,} 75 \mathrm{mg} / \mathrm{l}$ of adenine sulphate and $175 \mathrm{mg} / \mathrm{l}$ of ascorbic acid, for two weeks maintaining standard culture conditions of 25 $\pm 2{ }^{0} \mathrm{C}$ temperature, 60 per cent relative humidity and photoperiodic cycle of 16 hours light and 8 hours dark period. After two weeks of incubation, all the explants were evaluated for their ability to establish in liquid media. Healthy and contaminant free explants were excised by removing discolored tissue and transferred to baby jar bottles containing the MS semi-solid media supplemented with $4 \mathrm{mg} / \mathrm{l}$ of BAP and $75 \mathrm{mg} / \mathrm{l}$ of adenine sulphate for Nanjanagudu Rasabale and 175 $\mathrm{mg} / \mathrm{l}$ for Ney Poovan concentrations of ascorbic acid and incubated for four weeks 
maintaining standard culture conditions mentioned above. They were cultured in the same media and incubated for 4 weeks. There aseptic multiple cultures were subjected to gamma irradiation treatments as per experiment.

The proliferated cultures were sub cultured on to fresh multiplication media 25-30 days after incubation for further shoot multiplication. Totally five subculture $\left(\mathrm{M}_{1} \mathrm{~V}_{1}\right.$ to $\left.\mathrm{M}_{1} \mathrm{~V}_{5}\right)$ were carried out to minimize the problem of chimeras.

Induction of variation by gamma irradiation

Aseptic culture were subjected to gamma irradiation treatment at 25,30,35, 40 and 45 Gy at Baba Atomic Research Centre, Trombay using ${ }^{60} \mathrm{Co}$ as source of the gamma irradiation. Each treatment was replicated 3 times and about 30 multiple buds used for each treatment. Irradiated shoot tips were inoculated on fresh MS-medium supplemented with BAP $4 \mathrm{mg} / \mathrm{l}$ within 48 hours.

\section{Primary and Secondary Hardening}

After rooting, plantlets were taken out from culture bottles and washed thoroughly to remove agar medium adhered to roots. The plantlets were treated with $1 \%$ Bavistin for 5 minutes. Later plantlets were transferred to pro-tray containing sterilized cocopeat and kept under green house for 4 weeks. Plants were further transferred to polybags containing Red soil + Sand + FYM (1:1:1 v/v) potting mixture and raised under shade house for six weeks.

Screening of in vitro derived putative mutants for resistance against $\mathrm{FOC}$

Fusarium oxysporum f.sp. cubense (FOC) culture was obtained from Indian Type culture Collection Identification/Culture Supply Services, Division of Plant Pathology, Indian Agriculture Research Institute, New Delhi. For isolation and maintenance of pathogen, potato dextrose agar (PDA) media was used. The haemocytometer was used for counting the fungal spores in liquid suspension.

\section{Methodology of FOC Race 1 inoculation}

The variants of Nanjanagudu Rasabale and Ney Poovan obtained were screened against FOC using the procedure given by the Musoke, et al., (1999). Screening was carried out using FOC spore population adjusted to 3 x $10^{4}$ spores $\mathrm{ml} / \mathrm{l}$.

Each 3 month old plantlet after hardening was inoculated at 5 to $10 \mathrm{~cm}$ soil depth near the root zone with $3 \%$ of the spore suspension. Untreated control plantlets were inoculated with distilled water. The observations were taken at 60 days interval after pathogen inoculation.

Mutants were classified on the basis of vascular invasion of corm

The plants with symptom of brown discoloration in the root core of pseudostem and rhizome are as vascular invasion of $F O C$ (Bhagwat and Duncan, 1998)

The resistant/ tolerant/susceptible reaction of the Ney Poovan and Nanjanagudu Rasabale mutant against Fusarium wilt was assessed by the above disease rating scale developed by Ploetz et al., (1999) (Table 1).

\section{Molecular characterization}

DNA was extracted from in vitro derived mutants using young cigar leaf. Standard protocol for the isolation and extraction of DNA by CTAB method was used. SSR primers were used in this study. PCR was 
carried out using Model Master Cycle gradient 2551 (Eppendorf, Germany). Agarose gel electrophoresis was used because it gives better separation and visualization of PCR amplified products agarose is polysaccharide derived of agar contains micro pores and hence acts as molecular sieve. Following are the steps involved in setting up of agarose gel electrophoresis for accomplish the visualization of amplified bands

\section{Gel scoring}

It was done to identify resistant specific band (band which is present in resistant mutant and absent in susceptible individuals) and for testing variation among various morphological mutants, it was expected that the resistant specific band should be present in resistant mutants.

\section{Results and Discussion}

Hardened plants obtained after mutagenesis was subjected to early screening for any acquired resistance to FOC Race 1 .

Screening gamma ray irradiated in vitro derived putative mutants of banana cv. Nanjanagudu Rasabale against FOC Race 1

The data pertaining to screening of in vitro derived Nanjanagudu Rasabale mutants obtained from gamma ray irradiation mutagens revealed that there was disease development in the mutants due to artificial inoculation (Table 2).

\section{Number of plants inoculated}

A total of 90 Nanjanagudu Rasabale putative mutants (15 plants) from each treatment were selected having three to four leaf stages after secondary hardening plantlets. The plantlets were inoculated with $F O C$ Race 1.

\section{Number of plants died after inoculation}

Among the total 90 putative mutant screened, in which 63 plants were died. The highest numbers of plants (15 and 12) were died in doses of gamma irradiation $25 \mathrm{~Gy}$, untreated control, 30 Gy and 35 Gy. The lowest was in (5 and 4) in 40 Gy and 45 Gy, respectively.

\section{Number of plants with external symptoms of $\mathrm{FOC}$}

The reactions of putative mutants screened against FOC inoculated exhibited several peculiar symptoms like yellowing, wilting and stem splitting. The combined effect of the symptoms based on the symptoms (yellowing. wilting and stem splitting) was included among three symptoms based on the severity. The data pertaining to disease symptoms of the mutants are presented in the Table 2 .

\section{Yellowing}

Among the different doses of gamma ray irradiated mutants of Nanjanagudu Rasabale, the highest (10 and 9 plants) yellowing was observed in 40, 30, 45 Gy and untreated control. The lowest 8 plants were observed in 25 Gy and 35 Gy. The total 53 plants showed yellowing symptoms among irradiated and untreated control putative mutants.

\section{Wilting}

Results revealed that among the different doses mutagenic treatment in Nanjanagudu Rasabale had highest wilting (5) symptoms was recorded in $35 \mathrm{~Gy}$, followed by 4 plants in $25 \mathrm{~Gy}, 30 \mathrm{~Gy}$ and $45 \mathrm{~Gy}$. The lowest symptoms (2 and 3) were recorded in $40 \mathrm{~Gy}$ and untreated control. The total 22 plants showed wilting symptoms among irradiated and untreated control putative mutants of Nanjanagudu Rasabale. 


\section{Stem splitting}

Among the different doses of gamma ray irradiated mutants, the highest (3 plants) stem splitting was observed in $25 \mathrm{~Gy}$ and untreated control, followed by (2 plants) in 30 Gy and lowest was 1 plant was observed in $35 \mathrm{~Gy}$.

The total 9 plants showed stem splitting symptoms among irradiated and untreated control putative mutants of Nanjanagudu Rasabale.

Number of plants with no external symptoms of $\mathrm{FOC}$

The effect of $F O C$ culture on in vitro derived mutants of Nanjanagudu Rasabale was found to be effective in inducing resistant plants among the treatments.

The number of pants (3) with no external symptoms was observed in $40 \mathrm{~Gy}$. The treatment 45 Gy had 2 plants and 1 plant in 35 Gy with no external symptoms. The total 6 plants were observed with no external symptoms of $F O C$.

\section{Vascular invasion of corm}

The data pertaining to vascular invasion of the corm presented in Table 4. Plants exhibiting vascular invasion are categorized into light, medium and heavy.

Light vascular invasion of corm was the highest in 40 Gy (8.2). The lowest light vascular invasion was observed in $25 \mathrm{~Gy}$ (2.9).Medium vascular invasion of corm was more in untreated control (27).

The minimum medium vascular invasion was observed in 40 Gy (13).Heavy vascular invasion of corm was more in untreated control (38). The minimum heavy vascular invasion was observed in $40 \mathrm{~Gy}$ and $45 \mathrm{~Gy}$ (30) (Fig. 1).
Screening of gamma ray irradiated in vitro derived putative mutants of banana cv. Ney Poovan bale against $F O C$ Race 1

The data pertaining to screening of in vitro derived Ney Poovan bale mutants obtained from gamma ray irradiation revealed (Table 3 ) that there was disease development in the mutants due to artificial inoculation

\section{Number of plants inoculated}

A total of 90 Ney Poovan putative mutants (15 plants) from each treatment were selected having three to four leaf stages after secondary hardening plantlets. The plantlets were inoculated with $F O C$ Race 1.

\section{Number of plants died after inoculation}

Among the total 90 putative mutant screened, in which 61 plants were died. The highest number of plants (12, 10, 10 and 15) was died in doses of gamma irradiation $25 \mathrm{~Gy}, 30 \mathrm{~Gy}$, 35 Gy and untreated control. The lowest was in 40 Gy and 45 Gy treatment (8 \& 6), respectively.

\section{Number of plants with external symptoms of $\mathrm{FOC}$}

The reactions of putative mutants were screened against FOC inoculated exhibited several peculiar symptoms like yellowing, wilting and stem splitting. The combined effect of the symptoms based on the symptoms (yellowing. wilting and stem splitting) was included among three symptoms based on the severity. The data pertaining to disease symptoms of the mutants are presented in the (Table 3 Fig. 2).

\section{Yellowing}

Among the different doses of gamma ray irradiated mutants, the highest (11 plants) 
yellowing was observed in 30 Gy and untreated control, followed by 10 plants was observed in 25, 35 and 45 Gy. The lowest ( 9 plants) yellowing was observed in $40 \mathrm{~Gy}$. The total 61 plants showed yellowing symptoms on irradiated and control plants.

\section{Wilting}

Results revealed that among the different doses of mutagenic treatment the highest wilting (3 plants) symptoms was recorded in 25, 30 and 35 Gy fallowed by untreated control and 40 Gy 2 plants each. The lowest symptom (1 plant) was recorded in $45 \mathrm{~Gy}$. The total 14 plants showed wilting symptoms among irradiated and control plants

\section{Stem splitting}

Among the different doses of gamma ray irradiated mutants, highest (2 plants) stem splitting was observed in 25, 35, 40 Gy and untreated control and lowest was 1 plant was observed in 30 and 45 Gy. The total 10 plants showed stem splitting symptoms among irradiated and untreated control putative mutants.

\section{Number of plants with no external symptoms of $F O C$}

The effect of FOC culture on in vitro derived mutants was found to be effective in inducing resistant plants among the treatments. The number of pants (3) with no external symptoms was observed in $45 \mathrm{~Gy}$. The treatment 45 Gy had 2 plants with no external symptoms. The total 5 plants were observed with no external symptoms of FOC Race 1.

\section{Vascular invasion of corm}

The data pertaining to vascular invasion of the corm presented in Table 4. Plants exhibiting vascular invasion are categorized into light, medium and heavy (Fig. 3).
Light vascular invasion of corm was highest in 45 Gy (9.3). The lowest light vascular invasion was observed in untreated control (2.2). Medium vascular invasion of corm was more in untreated control (29). The minimum medium vascular invasion was observed in 40 Gy (12). In the present study, out of the 90 mutants each evaluated from both the banana cultivar 5 and 6 mutants were found to be highly tolerant in Nanjanagudu Rasabale, respectively to $F O C$ race 1 pathogen.

External symptoms exhibited by the plants included leaf yellowing, wilting and pseudostem splitting were recorded. The effects of $F O C$ culture on various gamma ray irradiated mutants showed varied symptoms. The injured roots of the in vitro derived plantlets before inoculation of $F O C$ spore suspension in soil, showed symptoms of $F O C$ within fifth day of incubation. The leaf veins showed chlorosis gradually entire lamina turned yellow and resulted in the wilting of the leaves as reported by Krishna et al., (2013). The partially resistant plantlets exhibiting the symptoms were recorded. Among the plants inoculated maximum external symptoms were exhibited by unirradiated plants which showed maximum susceptibility to FOC. Probably this may be attributed to the difference response of the genomic composition of the cultivar to $F O C$ culture.

Heavy vascular invasion of corm was more in untreated control (36). The minimum heavy vascular invasion was observed in $40 \mathrm{~Gy}$ and 45 Gy (3). Data analyzed from the mutant plants screened against $F O C$ showed varied vascular invasion of corms. Light and medium vascular invasion of corm was less in plant derived from untreated control treatment. Stover and Malo (1972) reported that symptoms of $F O C$ often do not develop in banana plants growing in containers. However, the extent of rhizome invasion in 
container grown plants is correlated with symptoms in field grown plants are susceptible to the fungus.

\section{Analysis by SSR markers for gamma ray irradiated mutants}

Simple sequence repeats (SSR) markers were used to detect variation among gamma irradiated mutants of resistant, moderately resistant, susceptible mutants and the mother plant against $F O C$. 15 SSR markers were used to determine genetic variation between the various morphological mutants, resistant and susceptible mutants along with mother plant are produced in, Nanjanagudu Rasabale (AAB) and Ney Poovan (AB) Table 5.

Among the 15 primers showed 4 primers showed amplification and 4 primers amplified unambiguous, readable and showed polymorphic bands in, Nanjanagudu Rasabale (2) and Ney Poovan (2). A total of 42 amplified products were produced from the selected 4 primers, in which 18 bands were amplified by Nanjanagudu Rasabale and 24 bands were amplified by Ney Poovan mutants.

The number of bands varied from 1-2 with an average 1.33 bands per primers and the size ranged from 0.2 to $1.5 \mathrm{~kb}$. The bands which are more than $100 \mathrm{~kb}$ are selected for analysis. A polymorphism was found among the mutants and mother plant indicating there is a molecular variability among the mutants.
The 4 primers used provided a large number of polymorphism among the resistant, moderately resistant, susceptible mutants and mother plant. Only few of bands observed to be specifically shared either by resistant, moderately resistant, susceptible mutants and mother plant. Nanjanagudu Rasabale putative mutants amplified with Ma 3/2 showed the major bands $\approx 150$ bp shared by all resistant and moderately resistant mutants and varied from susceptible mutants and mother plant showed bands $\approx 180 \mathrm{bp}$. MA 15 showed the major bands $\approx 500$ bp shared by all resistant and moderately resistant mutants and varied from susceptible mutants and mother plant showed bands $\approx 280$ bp (Fig. 4 and 5).

Putative mutants of Ney Poovan bale amplified with Ma 1/17 showed the major band of 500 bp shared by all resistant and moderately resistant mutants and varied from susceptible mutants and mother plant. STMS 7 showed the major band $245 \mathrm{bp}$ shared by all resistant and moderately resistant mutants and varied in susceptible mutants and mother plant $\approx 250$ bp (Fig. 5 and 6 ).

Putative resistant and susceptible mutants showed variation in the banding pattern in Ney Poovan and Nanjanagudu Rasabale. This clearly indicates the changes under molecular level. These bands may be associated with the resistant character of putative mutants. SSR marker screening in four banana cultivar confirms that they are linked to disease resistance genes (Fig. 7).

Table.1 Disease rating scale

\begin{tabular}{|c|l|l|}
\hline Scale & \multicolumn{1}{|c|}{ Grade } & \multicolumn{1}{c|}{ Symptoms } \\
\hline 0-1 \% & Immune/Resistant & Healthy (No symptoms) \\
\hline Light (<10\%) & Highly Resistant & Slight chlorosis and wilting \\
\hline Medium (10-30 \%) & Moderately resistant & Moderate chlorosis and wilting with of leaf blade \\
\hline Heavy (> 30 \%) & Susceptible & $\begin{array}{l}\text { Sever chlorosis, wilting dwarfing of newly } \\
\text { emerged leaves or completely dead }\end{array}$ \\
\hline
\end{tabular}


Table. 2 The reactions of gamma ray reactions of gamma ray irradiated Nanjanagudu Rasabale to artificial inoculation of FOC under greenhouse conditions

\begin{tabular}{|c|c|c|c|c|c|c|}
\hline \multirow{2}{*}{$\begin{array}{c}\text { Gamma } \\
\text { irradiation/ } \\
\text { Cultivars }\end{array}$} & \multirow{2}{*}{$\begin{array}{l}\text { Number of } \\
\text { plants } \\
\text { inoculated }\end{array}$} & \multirow{2}{*}{$\begin{array}{l}\text { Number of } \\
\text { plants died } \\
\text { after } \\
\text { inoculation }\end{array}$} & \multicolumn{3}{|c|}{$\begin{array}{c}\text { Number of plants with } \\
\text { external symptoms of } F O C\end{array}$} & \multirow{2}{*}{$\begin{array}{l}\text { Number of } \\
\text { plants with } \\
\text { no external } \\
\text { symptoms }\end{array}$} \\
\hline & & & Yellowing & Wilting & $\begin{array}{c}\text { Stem } \\
\text { splitting }\end{array}$ & \\
\hline 25 Gy & 15 & 15 & 8 & 4 & 3 & 0 \\
\hline 30 Gy & 15 & 12 & 9 & 4 & 2 & 0 \\
\hline 35 Gy & 15 & 12 & 8 & 5 & 1 & 1 \\
\hline $40 \mathrm{~Gy}$ & 15 & 5 & 10 & 2 & 0 & 3 \\
\hline 45 Gy & 15 & 4 & 9 & 4 & 0 & 2 \\
\hline $\begin{array}{l}\text { Untreated } \\
\text { (Control) }\end{array}$ & 15 & 15 & 9 & 3 & 3 & 0 \\
\hline Total & 90 & 63 & 53 & 22 & 9 & 6 \\
\hline
\end{tabular}

Table.4 Effect of FOC on vascular invasion of corm in vitro gamma irradiated mutants of banana cv. Ney Poovan and Nanjanagudu Rasabale under greenhouse condition

\begin{tabular}{|c|c|c|c|c|c|c|}
\hline \multirow{2}{*}{$\begin{array}{c}\text { Gamma irradiation/ } \\
\text { Cultivars }\end{array}$} & \multicolumn{5}{|c|}{ Vascular invasion of corm } \\
\cline { 2 - 7 } & \multicolumn{7}{|c|}{ Nanjanagudu Rasabale } \\
\cline { 2 - 7 } & $\begin{array}{c}\text { Light } \\
(<\mathbf{1 0} \%)\end{array}$ & $\begin{array}{c}\text { Medium } \\
(\mathbf{1 0 - 2 0} \%)\end{array}$ & $\begin{array}{c}\text { Heavy } \\
(>\mathbf{3 0} \%)\end{array}$ & $\begin{array}{c}\text { Light } \\
(<\mathbf{1 0} \%)\end{array}$ & $\begin{array}{c}\text { Medium } \\
(\mathbf{1 0 - 2 0} \%)\end{array}$ & $\begin{array}{c}\text { Heavy } \\
(>\mathbf{3 0} \%)\end{array}$ \\
\hline $\mathbf{2 5}$ Gy & 2.9 & 25 & 35 & 3.9 & 28 & 30.2 \\
\hline $\mathbf{3 0 ~ G y}$ & 4.4 & 23 & 34 & 5.8 & 26 & 33 \\
\hline $\mathbf{3 5}$ Gy & 7.2 & 21 & 31 & 5.6 & 26 & 31 \\
\hline $\mathbf{4 0 ~ G y}$ & 8.2 & 13 & 30 & 8.2 & 12 & 30 \\
\hline $\mathbf{4 5}$ Gy & 8.0 & 12 & 30 & 9.3 & 14 & 30 \\
\hline Untreated (Control) & 3.6 & 27 & 38 & 2.2 & 29 & 36 \\
\hline
\end{tabular}

Table.3 The Irradiated putative mutants of banana cv. putative mutants of banana cv. Ney Poovan to artificial inoculation of FOC under greenhouse conditions

\begin{tabular}{|c|c|c|c|c|c|c|}
\hline \multirow{2}{*}{$\begin{array}{c}\text { Gamma } \\
\text { irradiation } \\
\text { / Cultivars }\end{array}$} & \multirow{2}{*}{$\begin{array}{c}\begin{array}{c}\text { Number } \\
\text { of plants } \\
\text { inoculated }\end{array} \\
\end{array}$} & \multirow{2}{*}{\begin{tabular}{|c|} 
Number \\
of plants \\
died after \\
inoculated
\end{tabular}} & \multicolumn{3}{|c|}{$\begin{array}{l}\text { Number of plants with external } \\
\text { symptoms } F O C\end{array}$} & \multirow{2}{*}{$\begin{array}{c}\text { Number of } \\
\text { plants with } \\
\text { no external } \\
\text { symptoms }\end{array}$} \\
\hline & & & Yellowing & Wilting & $\begin{array}{l}\text { Stem } \\
\text { splitting }\end{array}$ & \\
\hline 25 Gy & 15 & 12 & 10 & 3 & 2 & 0 \\
\hline $30 \mathrm{~Gy}$ & 15 & 10 & 11 & 3 & 1 & 0 \\
\hline 35 Gy & 15 & 10 & 10 & 3 & 2 & 0 \\
\hline $40 \mathrm{~Gy}$ & 15 & 8 & 9 & 2 & 2 & 2 \\
\hline 45 Gy & 15 & 6 & 10 & 1 & 1 & 3 \\
\hline $\begin{array}{l}\text { Untreated } \\
\text { (Control) }\end{array}$ & 15 & 15 & 11 & 2 & 2 & 0 \\
\hline Total & 90 & 61 & 61 & 14 & 10 & 5 \\
\hline
\end{tabular}


Table.5 List of SSR primers used for screening disease resistance in putative banana mutants

\begin{tabular}{|l|l|l|l|}
\hline Sr.No & \multicolumn{1}{|c|}{ Primer } & \multicolumn{1}{|c|}{ Forward } & \multicolumn{1}{c|}{ Reverse } \\
\hline $\mathbf{1}$ & Ma 15 & AGGCGGGGAATCGGTAGA & GGCGGGAGACAGATGGAGT \\
\hline $\mathbf{2}$ & Ma1 & TGAATCCCAATTTGGTAAG & CAAAACACTGTCCCCATCTC \\
\hline $\mathbf{3}$ & Ma 1/17 & TCGGCTGGCTAATAGAAGGAA & TCTCGAGGGATGGTGAAAGA \\
\hline $\mathbf{4}$ & MABN 34 & TAGGTGAGAATGGGACGGAG & CAGTAGCCAGCAACCTGGTGA \\
\hline $\mathbf{5}$ & CNPMF 43 & GTTTGGTGCTCATTGCTGTG & GTTTGGTGCTCATTGCTGTG \\
\hline $\mathbf{6}$ & MABN08 & TTACCGTAAACGGAGCCAAC & GAAATCGAGGAAAACCGACA \\
\hline $\mathbf{7}$ & Ma 3/2 & TGCGCGTCACACACACACA & GGCGATACGCAACAAATAGACTTAGG \\
\hline $\mathbf{8}$ & STMS 7 & AAGAAGGCACGAGGGTAG & CGAACCAAGTGAAATAGCG \\
\hline $\mathbf{9}$ & CNPMF 26 & TGGAGATGAAGAAGATCGTC & TCATCAAGTGCGTTGCATTC \\
\hline $\mathbf{1 0}$ & STMS 1 & TGAGGCGGGGAATCGGTA & GGCGGGAGACAGATGGAGTT \\
\hline $\mathbf{1 1}$ & MABN 03 & TGGTTGTATGTTTGCTGGGA & CAAAGTGCTGGCATGAGAAA \\
\hline $\mathbf{1 2}$ & MABN 06 & GCAACCATCAACCAAAAACC & TTTGCAAGAAAATCGTGCTG \\
\hline $\mathbf{1 3}$ & CNPMF 41 & GCTGCTCTCGCTTGTTATCC & GCTGCTCTCGCTTGTTATCC \\
\hline $\mathbf{1 4}$ & MABN07 & TTTTGATCATCATATGGGTCG & AGAGGGAGAGCCAAAGTGGT \\
\hline $\mathbf{1 5}$ & MABN13 & CCTCAACGAAGCATACAGCA & CAGTCTGGGCTGACACAGAA \\
\hline & & & \\
\hline
\end{tabular}

Fig.1 Response of gamma irradiated Nanjanagudu Rasabale mutants to FOC Race 1 on vascular invasion of plantlets

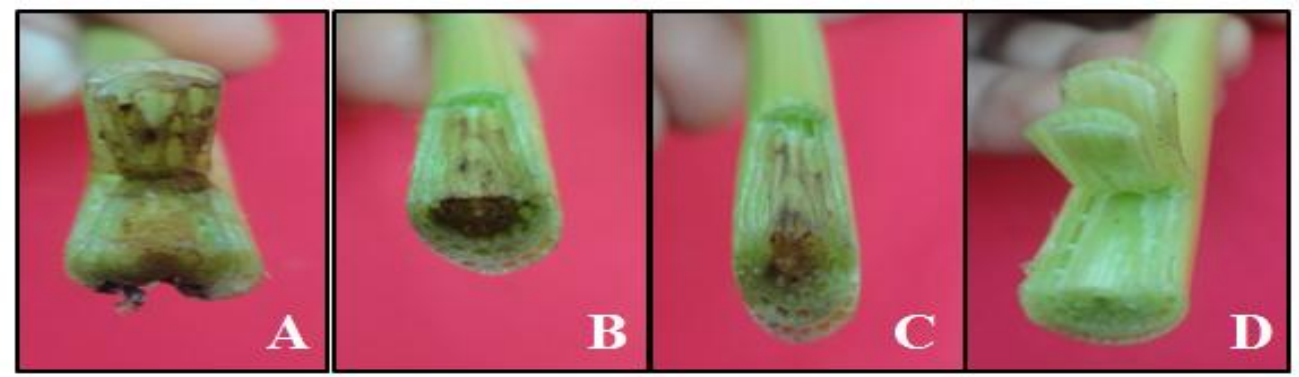

A. Heavy $>30 \%$, B. Medium $10-20 \%$, C. Light $<10 \%$, D. $0-1 \%$

Fig.2 External symptoms of putative mutants screened against $F O C$ inoculation

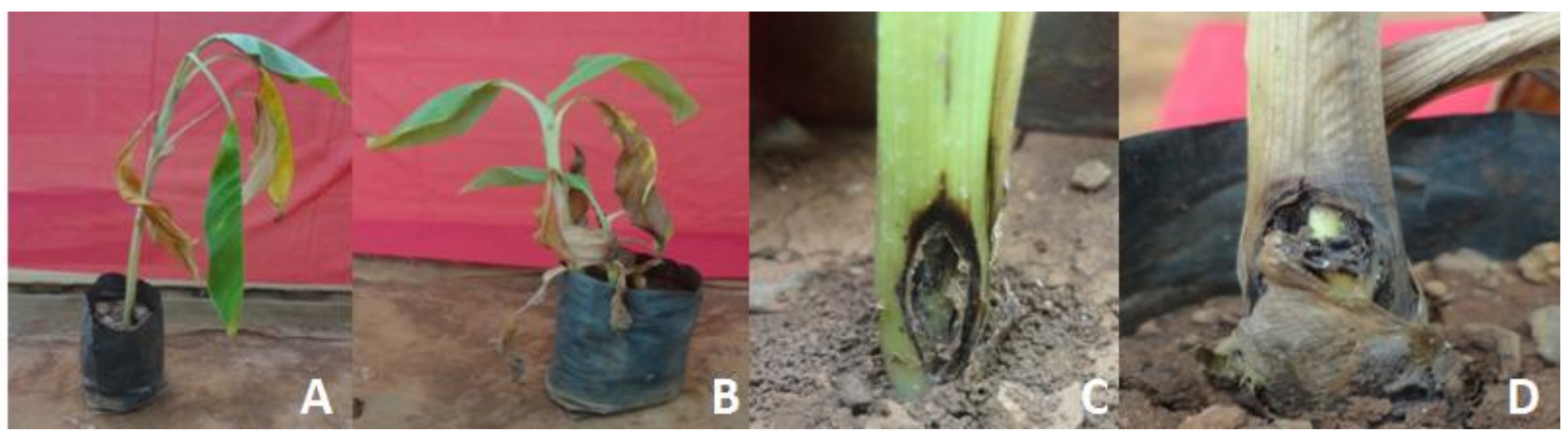

A. Yellowing and Wilting in Ney Poovan, B. Yellowing and Wilting in Nanjanagudu Rasabale, C. Stem splitting in Ney Poovan and D. Stem splitting in Nanjanagudu Rasabale 
Fig.3 Response of gamma irradiated Ney Poovan mutants to FOC Race 1 on vascular invasion of plantlets

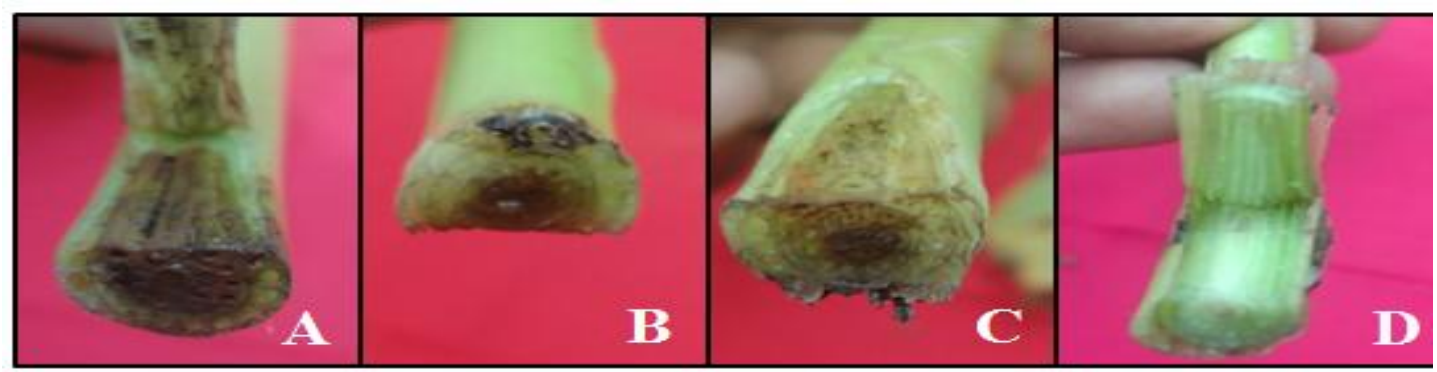

A. Heavy $>30 \%$, B. Medium $10-20 \%$, C. Light $<10 \%$, D. 0-1\%

Fig.4 SSR profile of control and gamma ray irradiated mutants of Nanjanagudu Rasabale obtained with Ma 3/2

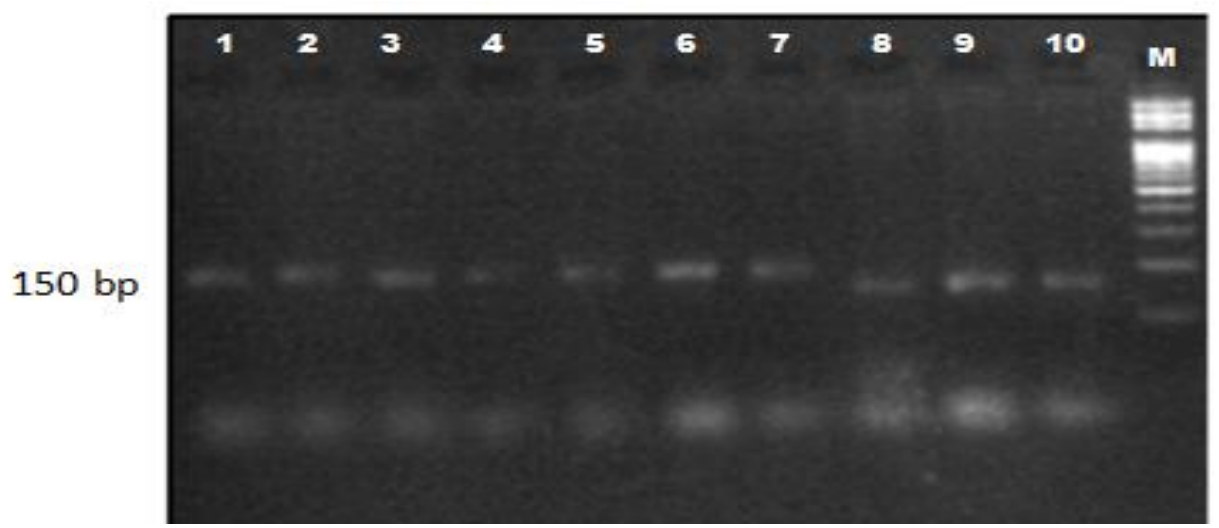

M- 100 bp Ladder, Moderately resistance: 1-35 Gy, 2-35 gy, 3-35 Gy, 4- 35 Gy, 5-40 Gy, 6-40 Gy, Resistance: 645 Gy, 7-45 Gy, Susceptible: 8-25 Gy, 9-30 Gy, 10 - Untreated (Control)

Fig.5 SSR profile of control and gamma ray irradiated mutants of Nanjanagudu Rasabale obtained with Ma 15

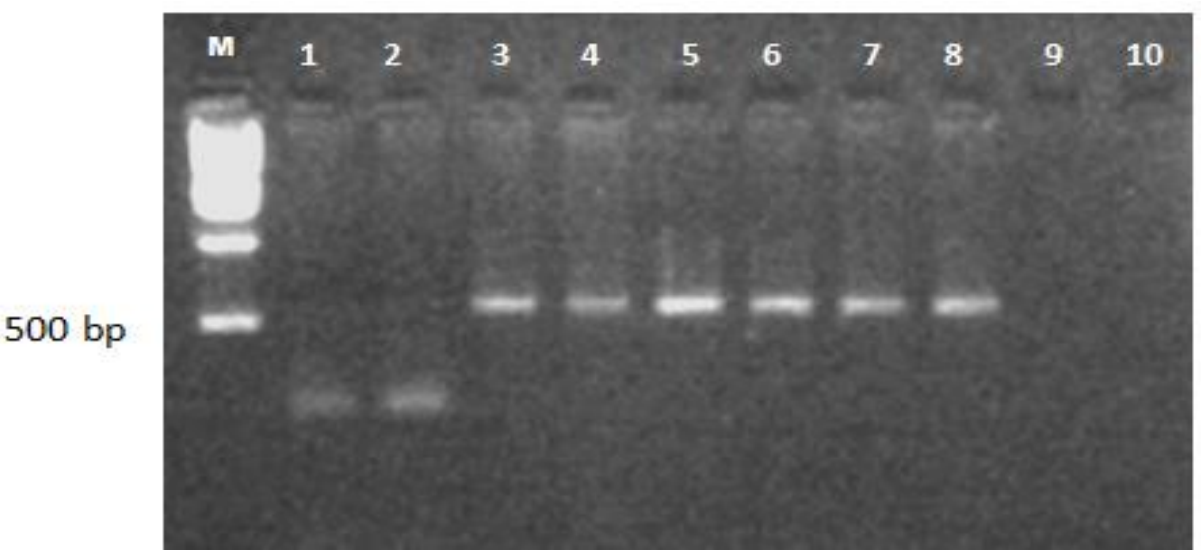

M- Ladder, 1- Untreated, Susceptible: 2- 25 Gy, Moderately resistance: 3-35 Gy, 4-35 Gy, 5-40 Gy, 6-40 Gy, 7-40 Gy, 8-40 Gy, Resistance: 9- 45 Gy, 10-45 Gy 
Fig.6 SSR profile of control and gamma ray irradiated mutants of Ney Poovan obtained with Ma 1/17

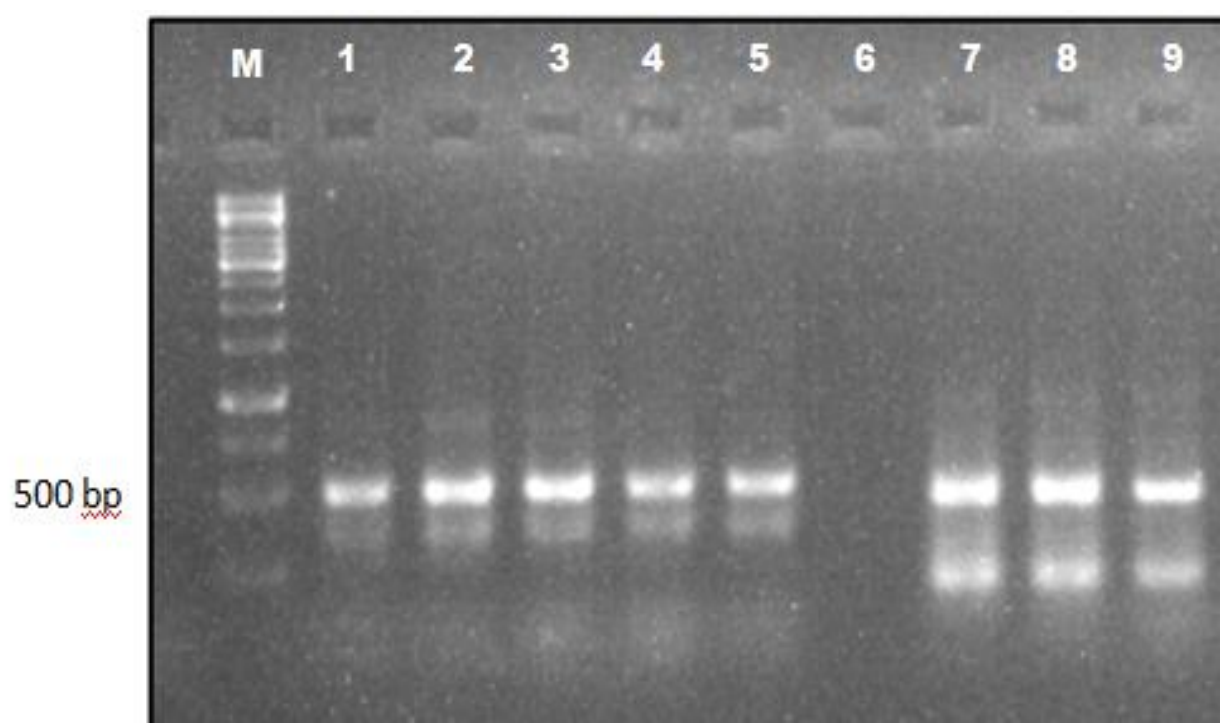

M- Ladder, 9- Untreated, Susceptible:7- 25 Gy, 8- 25 Gy, Moderately resistance: 1-35 Gy, 2-35 Gy, 3-30 Gy, 4-30 Gy, 5-35 Gy, Resistance: 6-45 Gy

Fig.7 SSR profile of control and gamma ray irradiated mutants of Ney Poovan obtained with STMS 7

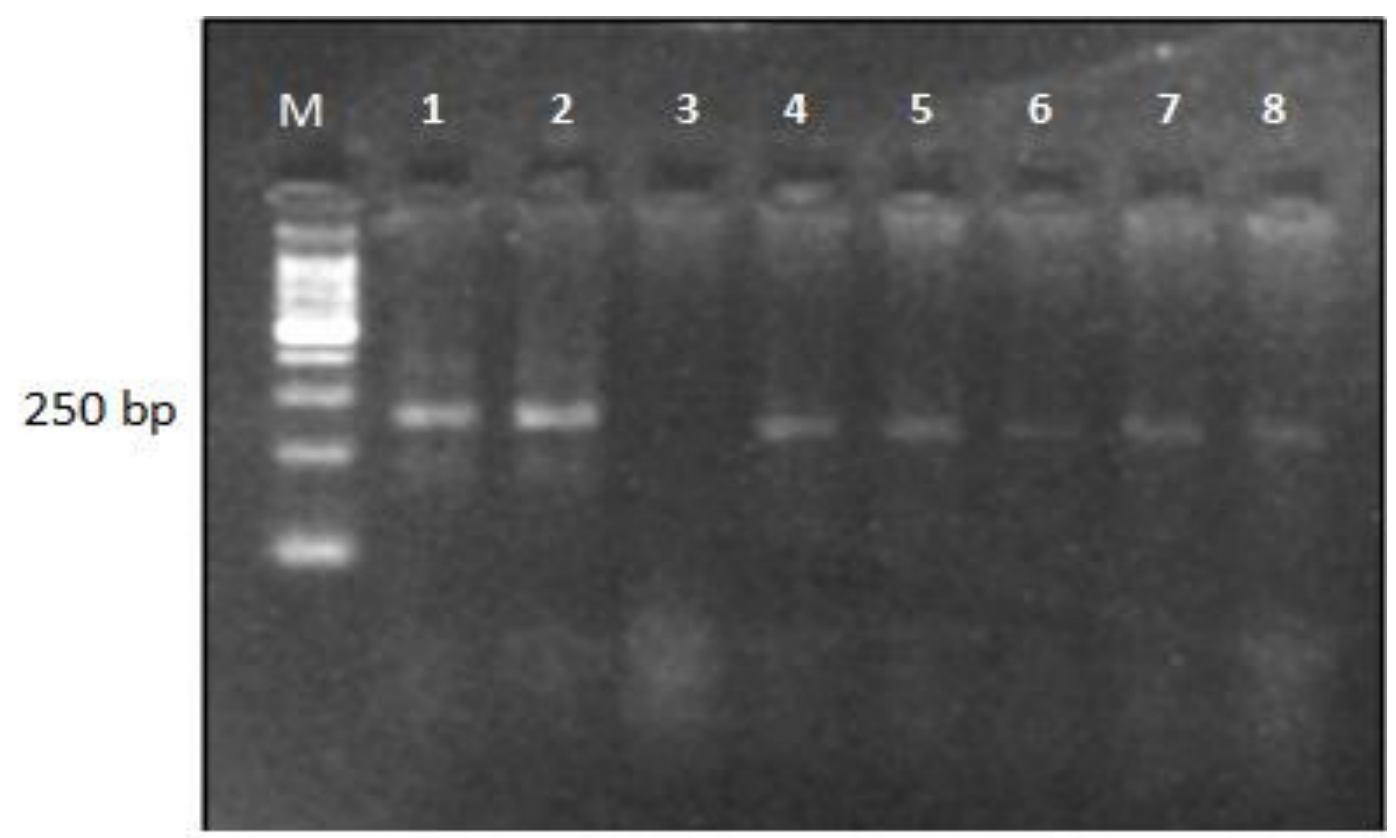

M-Ladder, 1- Untreated, Susceptible: 2-25 Gy, Moderately resistance: 4- 30 Gy, 5-40 Gy, 6-30 Gy, 7-35 Gy, 8-35 Gy, Resistance: 3-45 Gy 
It was reported that SSR marker GWM533 is closely linked to Sr2 gene Malik et al., 2013. Simple sequence repeat (SSR) based GWM533 and CAPS based CsSr2 markers reported for $\mathrm{Sr} 2$ gene were found promising for molecular confirmation of gene and have been used in stem rust breeding programmes in Australian, US and CIMMYT, Mexico (Spielmeyer et al., 2003; Mago et al., 2011). Chakraborty et al., (2015) identified the two sets of SSR markers, namely rbcL and matK were used to detect the presence or absence of PLB gene present in the shorter arm of chromosome 8 in the s1/s2 locus which confers resistance to purple blotch of onion. The presence band of PLB gene inferred the resistance.

Development of Fusarium wilt resistant in regionally grown banana crop is necessary to reduction of considerable yield losses. The conventional breeding method takes several years to develop cultivars from wild species. In the present study, the disease tolerance or susceptibility was based on the external symptoms observed after two months of FOC inoculation under green house conditions. Gamma ray irradiation is the potential tool and being highly used for crop to improve disease resistance. Gamma ray irradiation, a potent mutagen in plants and create point mutations easily. The mutant plant species can be easily selected from banana plants by SSR. This marker is reproducible and consistent as compared to morphological. The mutant plants produced by gamma ray irradiation are capable to tolerate Fusarium wilt in increased doses.

\section{References}

Bhagwat, B. and Duncan, E. J., 1998, Mutation breeding in banana cv. Highgate (Musa spp., AAA Group) for tolerance to Fusarium oxysporum f. sp. cubense using chemical mutagens.
Sci. Hortic., 73: 11-22.

Bidabadi, S. S., Sariah, M., Zakaria, W., Sreeramanan, S. and Maziah, M., 2012, Induced mutations for enhancing variability of banana (Musa spp.) shoot tip cultures using ethyl methanesulphonate (EMS). Aust. J. Crop Sci., 6 (3): 391-401.

Capdeville, G., Souza, M. T., Szinay, D., Wijnker, E. and De-Jong, H., 2009, The potential of high resolution BACFISH in banana breeding. Euphytica., 166: 431-443.

Chakraborty, M., Quddus, T., Rahman, S., Azad, M. S. K., Hossain, M. K., Hoque, A., Saha, M. K. and Haque, M. A., 2015, Molecular characterization of selected mutant lines of onion (Allium cepa L.) against purple leaf blotch disease using SSR Markers. Amer. J. of Expt. Agri., 8(4): 169-267.

Chopra, V. L., 2005, Mutagenesis: investigating the process and processing the outcome for crop improvement. Curr. Sci., 89: 353-359.

Daniells, J., Jenny, C., Karamura, D. and Tomekpe, K., 2001, Musalogue: A catalogue of Musa germplasm diversity in the genus Musa (Arunaud, E. and Sharrock, S. compil.). International Network for the Improvement of Banana and Platain, Montpellier, France 32(3): 314-331.

Khan, A. L., 2015, Only 30 acres for exotic Nanjangud Rasabale. The Hindu., Daily newspaper dated January 30.

Kishore H., 2016, Studies on induced mutations in banana cv. Nanjanagudu Rasabale (Musa spp., AAB), Group, University of horticultural Sciences, Bagalkot, Thesis.

Krishna, V. V., Kumar, K. G., Pradeepa, K., Kumar, S. R. S. and Kumar, R. S., 2013, Biochemical markers assisted screening of Fusarium wilt resistant 
Musa paradisiacal (L) cv. Puttabale micropropagated clones. Indian $J$. Exp. Biol., 51:531-541.

Mago, R., Guedira, B., Dreisigacker, S., Breen J., Jin, Y., Singh, R., Appels, R., Lagudah, E.S., Ellis, J. and Spielmeyer, W., 2011, An accurate DNA marker assay for stem rust resistance gene $\mathrm{Sr} 2$ in wheat. Theoretical and Applied Genetics. 122: 735-744.

Malik, R., Parveen, S., Saharan, M. S., Kumar, R., Sharma, A. K., Bhardwaj, S. G and Sharma, I. 2013, Characterization of stem rust resistance gene $\mathrm{Sr} 2$ in Indian wheat varieties using polymerase chain reaction (PCR) based molecular markers, African Journal of Biotechnology., 12(18), 2353-2359.

Musoke, C., Rubaihayo, R. P. and Magambo, M., 1999, Gamma rays and ethyl methane sulphonate in vitro induced Fusarium wilt resistant mutants in bananas. Afr. Crop Sci. J., 7 (4): $313-$ 320.

Pooja, B., Ajit, A.W. and Umesha, K., 2013, Preliminary assessment of intra-clonal variations in Indian banana varieties for sucker production, Ind. J. Natural products and resources, 4 (4): 387 391.

Pua, E. C., 2007, Banana. In: Pua EC, Davey MR (eds), Biotechnology in Agriculture and Forestry. SpringerVerlag., 60: 3-34.

Ravi, I., Uma, S., Vaganan, M. M. Mustaffa, M. M., 2013, Phenotyping bananas for drought resistance. Front. Physiol., 3:45-49.

Silva, S. O., Junior, M. S., Alves, E. J. Silveria, J. S. and Lima, M. B., 2001, Banana breeding program at EMBRAPA. Crop Breed. Appl. Biotechnol., 1(4): 399-436.

Spielmeyer, W., Sharp, P. J. and Lagudah, E. S., 2003, Identification and validation of markers linked to broadspectrum stem rust resistance gene $\mathrm{Sr} 2$ in wheat (Triticum aestivum L.). Crop Sci., 43:36.

Stover, R. H. and Malo, S. E., 1972. The occurrence of Fusarium wilt in normally resistant dwarf Cavendish banana. Pl. Dis. Reporter., 56 (11):1000-1003

\section{How to cite this article:}

Rashmi Hegde, .G Prabhuling, Kulpathi Hipparagi, A.G. Babu, C.P Mansur and Satish, D. 2019. In vitro Inductions of Gamma Ray Mutation for Fusarium Wilt Resistance and Characterization of Mutants in Regionally Grown Banana Cultivars. Int.J.Curr.Microbiol.App.Sci. 8(03): 1436-1448. doi: https://doi.org/10.20546/ijcmas.2019.803.168 